\title{
COMMENTARY
}

\section{Sparing brain damage in severe sepsis: a beginning}

\author{
G Bryan Young* \\ See related research by Spapen et al., http://ccforum.com/content/14/2/R54
}

\begin{abstract}
Sepsis-associated encephalopathy (SAE) resembles metabolic encephalopathies but with a difference: there is the potential for enduring brain damage/ dysfunction. The pathogenesis of SAE is likely multifactorial. However, the severity of SAE parallels the severity of the septic illness and the brain's microcirculation is probably affected in a similar manner to that of other organs. Mild cases of SAE are often completely reversible, but there is increasing evidence that severe cases have neurological sequelae. A better understanding of the mechanisms may lead to brain-sparing, protective strategies.
\end{abstract}

Spapen and colleagues in a recent issue of Critical Care [1] make the case that severe sepsis can cause potentially preventable brain damage. The brain is one of the first organs to fail in sepsis [2]. Sepsis-associated encephalopathy (SAE) parallels the failure of other organs in more advanced septic illness [3]. Mild cases may have delirium and mild electroencephalogram changes, but more seriously ill patients are comatose in ICU with suppressed electroencephalograms [3]. The disorder resembles metabolic encephalopathies, with intact brainstem function, fluctuating levels of consciousness and diffuse cerebral dysfunction. However, it is increasingly recognized that survivors of severe septic illness often have cognitive and social disabilities $[4,5]$. Microscopic infarctions, too small to be seen using magnetic resonance imaging, are sometimes found at post-mortem [6]. Areas of neuronal dropout, small hemorrhages and microabscesses are also seen in some cases [6]. Thus, there is evidence that advanced sepsis can cause brain damage. Milder cases may recover unscathed; these cases may relate to the

*Correspondence: bryan.young@lhsc.on.ca

Departments of Clinical Neurological Sciences and Medicine, The University of Western Ontario, London, Ontario, Canada N6A 5A5 other more reversible mechanisms of SAE, for example, neurotransmitter imbalances from altered amino acid ratios in the blood, dysfunction of other organs, transient alterations in blood-brain barrier function, slow clearance of sedative drugs, or only mild alterations in brain perfusion [7]. More advanced cases of sepsis and SAE may have neuron-killing complications: microcirculatory disturbances, excitotoxicity, oxidative stress and apoptotic mechanisms that also affect other organs [6]. Many of these complications are thought to arise from cytokine-mediated effects, either directly or indirectly acting on the microvasculature, coagulation system or on the organs themselves [8].

Until now there is no recognized treatment for SAE, other than to treat the systemic illness and hope that the brain will recover along with the other organs. However, the study by Spapen and colleagues [1] offers some hope that the brain can be helped and protected in SAE. The authors conducted a trial in which patients with sepsis received human recombinant activated protein C (APC). Patients with a Glasgow Coma Scale (GCS) score of less than 13 who received APC showed a reduction in blood concentrations of S100 $\beta$, a glial protein used as a marker of brain damage, compared to those who did not receive APC. In those whose GCS was 13 or greater there was no difference in $S 100 \beta$ levels between those who received and those who did not receive APC. There was also a considerable difference in grouped levels of APC between those with a GCS $>13$ versus those with a GCS of 13 or less.

Although the study by Spapen and colleagues [1] is preliminary, the results support the concept that severe sepsis can cause brain damage and that this is mediated, at least in part, by altering endothelial function and the microcirculation. (In this respect the brain may not be that different from other organs.) Milder cases of sepsis, as we have found clinically, may escape unscathed.

If we accept that the brain is injured in severe sepsis, we should follow the lead of Spapen and colleagues [1] and work towards other neuron-sparing measures, weighing potential adverse effects versus benefits. There may be other strategies - for example, trials of antioxidants - that are also worth considering. 


\section{Abbreviations}

APC $=$ activated protein $\mathrm{C} ; \mathrm{GCS}=$ Glasgow Coma Scale; SAE $=$ sepsisassociated encephalopathy.

\section{Competing interests}

The author declares that they have no competing interests.

Published: 21 May 2010

\section{References}

1. Spapen H, Nguyen DN, Troubleyn J, Huyghens L, Schiettecatte J: Drotrecogin alfa (activated) may attenuate severe sepsis-associated encephalopathy in clinical septic shock. Crit Care 2010, 14:R54.

2. Young GB, Bolton CF, Austin TW, Archibald YM, Gonder J, Wells GA: The encephalopathy associated with septic illness. Clin Invest Med 1990, 20:724-726.

3. Young GB, Bolton CF, Archibald YM, Austin TW, Wells GA: The electroencephalogram in sepsis-associated encephalopathy. J Clin Neurophysiol 1992, 9:145-152.
4. Lazosky A, Young GB, Zirul S, Phillips R: Quality of life after septic illness. J Crit Care 2009 [Epub ahead of print].

5. Rothenhäusler HB, Ehrentraut S, Stoll C, Schelling G, Kapfhammer HP: The relationship between cognitive performance and employment and health status in long-term survivors of the acute respiratory distress syndrome: results of an exploratory study. Gen Hosp Psychiatry 2001, 23:90-96.

6. Jackson AC, Gilbert JJ, Young GB, Bolton CF: The encephalopathy of sepsis. Can J Neurol Sci 1985, 12:303-307.

7. Wilson JX, Young GB: Progress in clinical neurosciences: sepsis-associated encephalopathy: evolving concepts. Can J Neurol Sci 2003, 30:98-105.

8. Vincent JL, Habib AM, Verdant C, Bruhn A: Sepsis diagnosis and management: work in progress. Minerva Anestesiol 2006, 72:87-96.

doi:10.1186/cc9010

Cite this article as: Young GB: Sparing brain damage in severe sepsis: a beginning. Critical Care 2010, 14:159. 